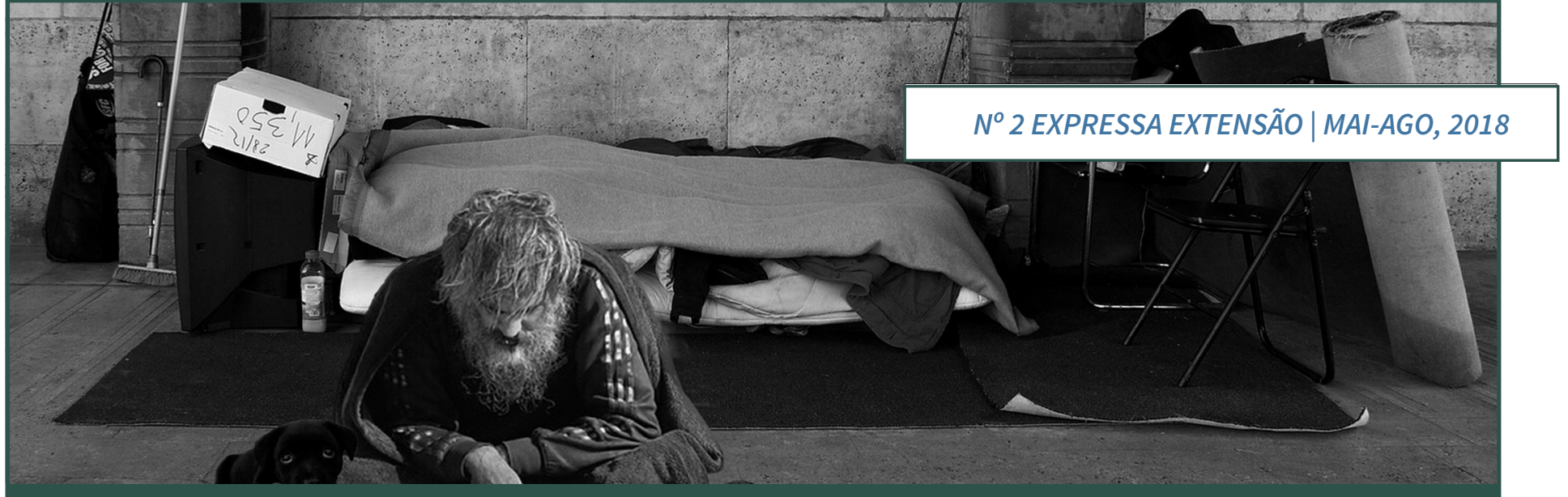

\title{
O PROCESSO SAÚDE-DOENÇA-CUIDADO À POPULAÇÃO EM SITUAÇÃO DE RUA: INTERVENÇÕES DE ACADÊMICOS DE ENFERMAGEM
}

THE HEALTH-CARE DISEASE PROCESS TO POPULATION IN STREET SITUATION:

INTERVENTIONS OF NURSING ACADEMICS

\author{
Luiza Jocymara Lima Freire Dias ${ }^{1}$ Maria Girlane Sousa Albuquerque Brandão² \\ Vitória Ferreira do Amaral $^{3}$ Maria Iranaid Linhares Aguiar ${ }^{4}$ \\ Ana Suelen Pedroza Cavalcante ${ }^{5}$ Maristela Inês Osawa Vasconcelos ${ }^{6}$
}

\section{RESUMO}

O Este estudo tem por objetivo descrever atividades realizadas com pessoas em situação de rua assistidas por um Centro de Referência Especializado para População em Situação de Rua de um município da Região Norte do Estado do Ceará. O projeto de intervenção refere-se à experiência de acadêmicos do curso de Enfermagem de uma Universidade no Estado do Ceará, vinculados a atividades de estágio curricular no módulo de Práticas Interdisciplinares em Ensino, Pesquisa e Extensão I (PIEPE I), no período de maio a julho de 2016. O projeto consistiu na realização de um conjunto de intervenções, buscando atingir, enquanto público-alvo, a população em situação de rua participante de um Centro de Referência Especializado para População em Situação de Rua. Foram realizados quinze encontros de intervenção, com uma média de dez participantes, que tiveram os seguintes temas definidos: Infecções sexualmente transmissíveis (IST); Métodos contraceptivos; Drogas lícitas e ilícitas; Dengue; Valorização dos pertences; A importância do lar, do trabalho e da família; Higienização corporal; Higienização bucal e prótese; Instrução de escovação; Instruções sobre câncer de boca. Foram

\footnotetext{
${ }^{1}$ Luiza Jocymara Lima Freire Dias - Universidade Estadual Vale do Acaraú - UVA - Brasil - Acadêmica de Enfermagem da Universidade Estadual Vale do Acaraú - UVA, luizajocymarafreire20@gmail.com; ${ }^{2}$ Maria Girlane Sousa Albuquerque Brandão - Universidade Estadual Vale do Acaraú - UVA - Brasil - Acadêmica de Enfermagem da Universidade Estadual Vale do Acaraú - UVA, girlane.albuquerque@yahoo.com.br; ${ }^{3}$ Vitória Ferreira do Amaral Universidade Estadual Vale do Acaraú - UVA - Brasil - Acadêmica de Enfermagem da Universidade Estadual Vale do Acaraú - UVA, vyctoriaamaral@gmail.com; ${ }^{4}$ Maria Iranaid Linhares Aguiar - Universidade Estadual Vale do Acaraú - UVA - Brasil - Acadêmica de Enfermagem da Universidade Estadual Vale do Acaraú - UVA, iranaidlinhares@gmail.com; ${ }^{5}$ Ana Suelen Pedroza Cavalcante - Universidade Federal do Ceará - UFC - Brasil - Enfermeira. Mestranda em Saúde da Família pela Universidade Federal do Ceará - UFC, anasuelen15@hotmail.com; ${ }^{6}$ Maristela Inês Osawa Vasconcelos - Universidade Estadual Vale do Acaraú - UVA - Brasil - Doutora em Enfermagem. Pós - Doutorado no Programa de Cuidados Clínicos em Enfermagem e Saúde. Docente da Universidade Estadual Vale do Acaraú - UVA, miosawa@gmail.com
} 
utilizadas metodologias ativas e participativas, onde os participantes puderam interagir com os temas e falar ativamente suas opiniões e expressar suas dúvidas. A realização dessas intervenções em um serviço de apoio às pessoas em situação de rua configurou-se como uma importante estratégia da Universidade para dar um retorno à comunidade e contribuir com uma melhor formação profissional. Logo, essas vivências contribuíram na melhor visualização do indivíduo na sua totalidade.

Palavras-chave: Promoção da saúde. Pessoas em situação de rua. Enfermagem em saúde comunitária.

\section{ABSTRACT}

This study aims to describe activities performed with people in the street situation assisted by a Specialized Reference Center for Population in Street Situation of a municipality in the Northern Region of the State of Ceará. The intervention project refers to the experience of academics of the Nursing course of a University in the State of Ceará, linked to activities of curricular internship in the module of Interdisciplinary Practices in Teaching, Research and Extension I (PIEPE I), in the period of May to July 2016. The project consisted in the accomplishment of a set of interventions, aiming at reaching, as a target audience, the street population participating in a Specialized Reference Center for Population in Situation of Street. Fifteen intervention meetings were held, with an average of ten participants, with the following themes defined: Sexually Transmitted Infections (STIs); Contraceptive Methods; Licit and illicit drugs; Dengue; Valuation of belongings; The importance of home, work and family; Body hygiene; Oral hygiene and prosthesis; Brushing instruction; Instructions on mouth cancer. Active and participative methodologies were used, where the participants were able to interact with the themes and actively speak their opinions and express their doubts. The implementation of these interventions in a support service for street people has been an important strategy of the University to give a return to the community and contribute to a better vocational training. Therefore, these experiences contributed in the best visualization of the individual in its totality.

Keywords: Health promotion. Street people. Community health nursing.

\section{INTRODUÇÃO}

Há um número cada vez maior de pessoas excluídas dos direitos sociais básicos, como educação, saúde, trabalho, moradia, lazer, segurança e outros até mesmo dos direitos humanos, com alguns grupos relegados à invisibilidade. É 
nessa categorização que encontramos as pessoas em situação de rua (PAIVA et al., 2016). Pessoas em situação de rua fazem parte de um segmento populacional heterogêneo, que não possui moradia e pernoita em logradouros públicos ou em unidades de acolhimento (NETO, 2016).

Existiam, em 2015, 101.854 pessoas em situação de rua no Brasil. A existência desse quantitativo de pessoas em situação de rua no Brasil é fruto do agravamento de inúmeras questões sociais. Diversos fatores colaboraram para esse agravamento e, consequentemente, para o crescimento da quantidade de indivíduos nessa situação, entre eles: a rápida urbanização ocorrida no século $X X$, à migração para grandes cidades, a formação de grandes centros urbanos, a desigualdade social, a pobreza, o desemprego, o preconceito da sociedade com relação a esse grupo populacional e, muitas vezes, a ausência de políticas públicas (BRASIL, 2014).

Viver nas ruas traz uma série de riscos, como exposição à violência, aumento das chances de contrair algum tipo de doença (física ou mental), dificuldade para alimentar-se, dependência de substâncias químicas, dentre outras, somando-se isso com o acesso precário aos serviços de saúde o indivíduo passa a ter uma qualidade de vida aquém do ideal. Aqui definida quanto à satisfação das necessidades individuais no âmbito de autorrealização nos critérios sociais, mentais e econômicos (SILVA; GUTIERREZ, 2013).

Mediante a essa realidade é perceptível à necessidade de uma assistência em saúde efetiva, que favoreça os cuidados de prevenção e tratamento desse grupo populacional que vive sob a exposição de riscos a doenças, vulneráveis a diversos tipos de violências, ingestão de água e alimentos contaminados, variações climáticas extremas e muitos outros e, sobretudo busque a integralidade do cuidado.

Dessa forma, entende-se que com a inserção da enfermagem nesse cenário, por meio da integração ensino-serviço é possível desenvolver ações educativas voltadas à saúde desse grupo populacional, visando à prevenção de agravos à saúde.

Este trabalho tem por objetivo descrever atividades realizadas com pessoas em situação de rua assistidas por um Centro de Referência Especializado para População em Situação de Rua de um município do interior do Ceará. 


\section{MÉTODOS}

O projeto de intervenção refere-se à experiência de acadêmicos do curso de Enfermagem de uma Universidade no Estado do Ceará, vinculados a atividades de estágio curricular no módulo de Práticas Interdisciplinares em Ensino, Pesquisa e Extensão I (PIEPE I), no período de maio a julho de 2016. O projeto consistiu na realização de um conjunto de intervenções, buscando atingir, enquanto público-alvo, a população em situação de rua frequentadora de um Centro de Referência Especializado para População em Situação de Rua de um município do interior do Ceará. O Módulo PIEPE tem como princípio o desenvolvimento de atividades pedagógicas interdisciplinares, de caráter extensionista, articulando encontros no território com pessoas em situações de vulnerabilidade social.

O número de participantes, conforme demanda estabelecida pelo Centro de Referência Especializado para População em Situação de Rua, foi de cerca de dez pessoas por encontro, com a prevalência de pessoas adultas jovens do sexo masculino, com média de vinte a quarenta anos. O grupo foi de caráter aberto, sendo que poderia ocorrer a entrada e a saída de membros no decorrer dos encontros.

O contato com o campo de estágio foi efetivado por meio de reuniões com a coordenação do Centro de Referência Especializado para População em Situação de Rua, a fim de estabelecer um vínculo inicial e levantar a possibilidade de realização do projeto no local. Com o convênio estabelecido, foram acordadas, junto a equipe, as temáticas a serem trabalhadas, considerando modificações de planejamento caso outras demandas surgissem ao longo dos encontros. Assim as ações foram planejadas e implementadas segundo a metodologia de roda de conversa.

O Centro de Referência Especializado para População em Situação de Rua do estudo dispõe dessa unidade há três anos, sendo formada por uma equipe multiprofissional em que se realizam atividades diárias, proteção social especializada, em função de atender, principalmente, as necessidades básicas dos usuários de alimentação, higiene e em alguns casos até moradia, devido à unidade adquirir alojamentos, sendo estes disponibilizados para os que se adequam melhor a obedecer às regras e horários que o Centro de Referência Especializado para População em Situação de Rua determina.

O trabalho prestado nesse serviço é oferecido no decorrer de toda a semana, de oito da manhã às duas da tarde com exceção aos finais de semana. Os moradores em situações de rua obtêm o serviço a partir do momento que procuram a unidade de forma espontânea e com desejos de mudanças, onde os profissionais sempre prezam pelo respeito à liberdade de cada um, se querem ou não permanecer e participar das atividades. 
Os temas definidos foram os seguintes: Infecções sexualmente transmissíveis (IST); Métodos contraceptivos; Drogas lícitas e ilícitas; Dengue; Valorização dos pertences; A importância do lar, do trabalho e da família; Higienização corporal; Higienização bucal e prótese; Instrução de escovação; Instruções sobre câncer de boca. No decorrer dessas explicações voltada à saúde bucal teve-se o apoio de um acadêmico de odontologia que colaborou com as instruções que o público presente tinha dúvidas.

Essa experiência aconteceu por meio de quinze encontros presenciais com o grupo, com atividades específicas de acordo com as necessidades identificadas pelos profissionais do local e da demanda dos encontros grupais. Os encontros ocorreram segundo um cronograma criado com base na disponibilidade do serviço e da agenda de aulas teóricas dos acadêmicos. Tinham tempo de duração variável entre três e quatro horas, carga horária definida com base nas atividades planejadas, bem como nas necessidades de fala dos participantes.

Em relação ao andamento dos encontros, em todas as sessões os coordenadores e os participantes se apresentavam e havia uma exposição dos objetivos do projeto devido à variabilidade dos membros ao longo dos encontros.

Os encontros seguiam três etapas: Acolhimento, Abordagem do tema e Avaliação. Na primeira etapa realiza-se o acolhimento, no qual os participantes realizavam a higienização corporal. Em seguida tinha-se a leitura da "Palavra do dia", constando de uma passagem bíblica, sendo ministrada algumas vezes por um padre ou uma freira que costumavam visitar o Centro, prestando apoio a essas pessoas vulneráveis, e até mesmo a leitura de algum texto motivacional que faziam refletir e os dava esperança de dias melhores, logo após era servido o café da manhã que era ofertado. Posteriormente, já na segunda etapa trabalhava-se o tema por diversos meios lúdicos, como, aula expositiva, vídeos, sessão de cinema, dinâmicas educativas e confecção de materiais. Por último, a terceira etapa dava-se pela realização da escuta das vivências pelos usuários que constituía na avaliação do momento.

\section{RESULTADOS}

Realizaram-se quinze encontros de intervenção com uma média de dez participantes. Foram utilizadas metodologias ativas e participativas, onde os participantes podiam interagir sobre os temas e falar ativamente suas opiniões e expressar suas dúvidas. O quadro I apresenta uma síntese das atividades de intervenção realizadas. 
Quadro 1 - Resumos das atividades realizadas com pessoas em situação de rua de um Centro de Referência Especializado para População em Situação de Rua, Ceará, 2016

\begin{tabular}{|c|c|c|c|c|}
\hline Ação & Mês & Tema da Atividade & Objetivo & Metodologia \\
\hline 01 & Maio & $\begin{array}{l}\text { Primeiro contato } \\
\text { com a coorde- } \\
\text { nação } \\
\text { Centro de Referên- } \\
\text { cia Especializado } \\
\text { para População } \\
\text { em Situação de } \\
\text { Rua }\end{array}$ & $\begin{array}{l}\text { Conhecer o ambiente e as } \\
\text { necessidades dos usuários. }\end{array}$ & $\begin{array}{l}\text { Diálogo com o coor- } \\
\text { denador e equipe e } \\
\text { posteriormente }\end{array}$ \\
\hline 02 & Maio & $\begin{array}{l}\text { Primeiro contato } \\
\text { com os usuários }\end{array}$ & $\begin{array}{l}\text { Explicar aos usuários sobre } \\
\text { a proposta do módulo de } \\
\text { Práticas Interdisciplinares } \\
\text { em Ensino, Pesquisa e Ex- } \\
\text { tensão I e ouvir deles quais } \\
\text { eram suas perspectiva e } \\
\text { como poderíamos contribuir. }\end{array}$ & $\begin{array}{l}\text { Roda de Conversa } \\
\text { com as pessoas em } \\
\text { situação de Rua que } \\
\text { estavam presentes }\end{array}$ \\
\hline 03 & Junho & $\begin{array}{c}\text { Responsabilidade } \\
\text { e Respeito ao } \\
\text { Próximo. }\end{array}$ & $\begin{array}{l}\text { Trabalhar a socialização } \\
\text { dos indivíduos que estavam } \\
\text { prestes a ganharem um lar } \\
\text { através dos programas soci- } \\
\text { ais do Governo }\end{array}$ & $\begin{array}{l}\text { Vídeo motivacional } \\
\text { e de depoimentos de } \\
\text { pessoas que também } \\
\text { ganharam uma casa. } \\
\text { Disponibilizou-se pa- } \\
\text { pel e lápis para que } \\
\text { pudessem expressar } \\
\text { as expectativas. }\end{array}$ \\
\hline 04 & Junho & $\begin{array}{l}\text { Infecções Sex- } \\
\text { ualmente Trans- } \\
\text { missíveis }\end{array}$ & $\begin{array}{l}\text { Explicar o que são as In- } \\
\text { fecções Sexualmente Trans- } \\
\text { missíveis, sintomas, causas, } \\
\text { ambiente propicio para } \\
\text { procurar ajuda }\end{array}$ & $\begin{array}{l}\text { Foi explanado por } \\
\text { meio de slides e com } \\
\text { a participação de } \\
\text { um Profissional do } \\
\text { Centro de Orientação } \\
\text { e Aconselhamento } \\
\text { Sorológico }\end{array}$ \\
\hline 05 & Junho & Motivação & $\begin{array}{c}\text { Apresentou-se um filme com } \\
\text { intuito de motiva-los e logo } \\
\text { após fizemos uma roda de } \\
\text { conversa para escuta-los } \\
\text { falarem sobre motivação. }\end{array}$ & $\begin{array}{c}\text { Foi adaptada uma } \\
\text { sala para realização } \\
\text { do Cinema e logo } \\
\text { após roda de con- } \\
\text { versa } \\
\end{array}$ \\
\hline 06 & Junho & $\begin{array}{l}\text { Higienização } \\
\text { Bucal }\end{array}$ & $\begin{array}{c}\text { Instruir sobre a higiene } \\
\text { bucal: Dicas sobre a higie- } \\
\text { nização correta da prótese } \\
\text { dentária, escovação, falou-se } \\
\text { sobre câncer de boca e por } \\
\text { fim foi realizada a escovação } \\
\text { supervisionada e em seguida } \\
\text { a aplicação de flúor. }\end{array}$ & $\begin{array}{l}\text { Slides e Roda de } \\
\text { conversa com a } \\
\text { participação de um } \\
\text { Acadêmico do } 8^{\circ} \\
\text { Semestre de Odonto- } \\
\text { logia. }\end{array}$ \\
\hline
\end{tabular}




\begin{tabular}{|c|c|c|c|c|}
\hline 07 & Junho & $\begin{array}{l}\text { Higienização das } \\
\text { mãos }\end{array}$ & $\begin{array}{c}\text { Falar sobre a importância } \\
\text { de higienizar as mãos com o } \\
\text { intuito de fazerem adotarem } \\
\text { essa prática. }\end{array}$ & $\begin{array}{l}\text { Apresentação de } \\
\text { slides, vídeos curtos } \\
\text { e demonstração da } \\
\text { lavagem das mãos. } \\
\text { Logo após teve a } \\
\text { pratica dos partici- } \\
\text { pantes. }\end{array}$ \\
\hline 08 & Julho & Atividades Físicas & $\begin{array}{c}\text { Foi discutido a importân- } \\
\text { cia da atividade física para } \\
\text { combater doenças crônicas } \\
\text { como hipertensão e diabe- } \\
\text { tes. }\end{array}$ & $\begin{array}{l}\text { Breve roda de con- } \\
\text { versa e logo após } \\
\text { teve uma prática de } \\
\text { atividades físicas } \\
\text { com o auxilio de um } \\
\text { profissional educador } \\
\text { físico. }\end{array}$ \\
\hline 09 & Julho & $\begin{array}{l}\text { Decoração para } \\
\text { festa junina. }\end{array}$ & Produção artesanal. & $\begin{array}{l}\text { Oficina para con- } \\
\text { fecção de bandei- } \\
\text { rinhas, balões juninos. }\end{array}$ \\
\hline 10 & Julho & Dengue & $\begin{array}{l}\text { Conversar sobre a dengue, } \\
\text { como poderiam suspeitar de } \\
\text { dengue e onde estaria mais } \\
\text { propicio a ser acometido por } \\
\text { essa patologia. }\end{array}$ & $\begin{array}{l}\text { Roda de conversa } \\
\text { em que foi utilizado } \\
\text { plaquinhas com per- } \\
\text { guntas sobre o tema. }\end{array}$ \\
\hline 11 & Julho & $\begin{array}{l}\text { Higiene e Cuida- } \\
\text { dos Pessoais }\end{array}$ & Prevenção de doenças & $\begin{array}{l}\text { Oficina sobre os } \\
\text { cuidados de saúde. }\end{array}$ \\
\hline 12 & Julho & Dificuldades & $\begin{array}{c}\text { Fazer com que os usuários } \\
\text { entendessem que toda pes- } \\
\text { soa passa por dificuldades e } \\
\text { para supera-las é necessário } \\
\text { alguém para ajudar e o Cen- } \\
\text { tro de Referência Especial- } \\
\text { izado para População em } \\
\text { Situação de Rua se enquadra } \\
\text { como esse suporte para } \\
\text { ajudá-los. }\end{array}$ & Dinâmica do Papel. \\
\hline 13 & Julho & $\begin{array}{l}\text { Abordagem nas } \\
\text { ruas }\end{array}$ & $\begin{array}{c}\text { Conhecer os locais que as } \\
\text { pessoas em situação de rua } \\
\text { ficam durante a noite, além } \\
\text { de ver se tem novas pes- } \\
\text { soas para que possa falar } \\
\text { da existência do Centro de } \\
\text { Referência Especializado } \\
\text { para População em Situação } \\
\text { de Rua. }\end{array}$ & Conversas individuais. \\
\hline 14 & Julho & $\begin{array}{l}\text { Métodos contra- } \\
\text { ceptivos. }\end{array}$ & $\begin{array}{l}\text { Falar sobre a importância } \\
\text { dos Métodos Contraceptivos } \\
\text { e onde podem encontrar. }\end{array}$ & $\begin{array}{l}\text { Artefato no modelo } \\
\text { do jogo da velha que } \\
\text { abordava o tema do } \\
\text { encontro. }\end{array}$ \\
\hline
\end{tabular}




\begin{tabular}{|c|c|c|c|c|}
\hline 15 & Julho & Festa Junina & $\begin{array}{c}\text { Festejar com os profission- } \\
\text { ais e usuários do Centro de } \\
\text { Referência Especializado } \\
\text { para População em Situação } \\
\text { de Rua a festa junina }\end{array}$ & $\begin{array}{c}\text { Momento de descon- } \\
\text { tração em que teve } \\
\text { danças e brincadeiras }\end{array}$ \\
\hline
\end{tabular}

Essas vivências propiciaram aos acadêmicos de enfermagem conhecimentos significativos para sua vida pessoal e profissional. Tendo trabalhado sua capacidade de ouvir e perceber as necessidades semelhantes e individuais apesentadas pelas pessoas com quem trabalharam. Além de terem estimulado sua capacidade de resolubilidade mediante suas percepções, realizaram planejamentos para as atividades com o propósito de colaborar da melhor forma com o público abordado. Vale ressaltar ainda o convívio com os demais profissionais do serviço, que são de extrema importância para o cuidado integral dos usuários.

\section{DISCUSSÃO}

A Extensão Universitária possui papel importante no que se diz respeito às contribuições que pode trazer frente à sociedade. A partir do momento em que há esse contato entre o universitário e a sociedade, acontece por parte dos dois lados, benefícios. Aquele que está na condição do aprender acaba aprendendo muito mais, pois se torna muito mais gratificante praticar a teoria recebida dentro da sala de aula (RODRIGUES et al., 2013). Além de mediadora desse processo dialético de teoria/prática/ reflexão/prática, a extensão universitária é interdisciplinar, o que favorece a visão integrada de todas as dimensões da realidade social (FERRAZ et al., 2017).

A realização dessas intervenções em um serviço de apoio às pessoas em situação de rua configura-se como uma importante estratégia da Universidade para dar um retorno à comunidade e contribuir com uma melhor formação profissional. Com essa finalidade os estudantes tiveram trocas de experiências, foram oportunizados a atuarem no serviço e os mesmo deram sua contribuição. Nessas ações os usuários do serviço foram estimulados ao protagonismo, motivados a um melhor convívio social, conheceram precauções necessárias à vida voltadas à saúde física e mental, além de terem sido ouvidos sobre os motivos que acarretaram a vivência nas ruas.

Mediante o conhecimento sobre esse público e a convivência durante as ações foi possível compreender que essas pessoas possuem uma comum condição de pobreza absoluta e que na grande maioria estão com vínculos familiares interrompidos ou fragilizados, além da falta de habitação regular. Dentro desse contexto são compelidos a utilizarem a rua como espaço de moradia e conse- 
guem seu sustento de forma temporária ou permanente. É um processo de fragilização os vínculos interrompidos com o eixo familiar e que pode acarretar em solidão e desapego social, encontrando nas drogas uma forma de preencher esse vazio (ALCANTARA, 2015).

A maioria dos usuários relatou estar nessa condição devido ao uso de drogas lícitas e ilícitas, dando maior visibilidade para o álcool, maconha, crack e cocaína. Em consequência da dependência dessas drogas praticavam furto dentro da própria moradia, além de viverem em constantes conflitos que resultaram nas relações familiares desconstruídas (PAIVA et al., 2016). Segundo esse autor as principais causas que levam as pessoas a viverem nas ruas estão relacionadas ao alcoolismo e/ou drogas (35,5\%), desavenças com pai/mãe/irmãos $(29,1 \%)$ e desemprego $(29,8 \%)$.

Já a minoria dos indivíduos expôs que estavam assim por escolha, pois preferiam estar nas ruas a causar preocupação e sofrimento para a família, sendo assim, os usuários se faziam pertencentes a essa realidade. Quanto maior o tempo que permanecem nas ruas, independente que esteja recente, ou seja, uma situação circunstancial, maior é a possibilidade de se tornarem permanentes como seres da rua (PAIVA et al., 2016).

Mas além desses, também havia usuários que não compartilhavam da mesma realidade, frequentavam o Centro por motivos de não serem natural da cidade e estarem desempregados, sempre afirmando que ao sair de tal condição não retornariam mais ao Centro de Referência Especializado para População em Situação de Rua de um município do interior do Ceará, apesar de destacarem a importância desse serviço.

Nos momentos de acolhimento foi possível estabelecer relação entre o cotidiano dos integrantes e as reflexões emergidas, trabalhando ainda o aspecto motivacional em suas realidades e abordagens sobre doenças as quais estão mais vulneráveis, devido sua situação de vida. Durante as ações, foi evidenciado sentimento de pertencimento a situação de vida atual dessa população, apesar das ações de inclusão desenvolvidas pelo Centro de Referência Especializado para População em Situação de Rua de um município do interior do Ceará. O sentimento de pertencer à sociedade depende das relações dos indivíduos, onde vivem e as pessoas de sua convivência (ALCANTARA, 2015).

Observou-se a participação ativa dos usuários durante as oficinas, demonstrando conhecimento prévio sobre as temáticas abordadas, favorecendo um trabalho colaborativo entre usuários, profissionais e estudantes. Descontruir o tratamento de invisibilidade para com as pessoas em situação de rua e romper com o pensamento comum de que mendigo é vagabundo podem ser essenciais para resgatar a cidadania desse povo (PAIVA et al., 2016). 
Além disso, foi possível que os acadêmicos de enfermagem dessem seguimento a um projeto de inclusão digital, onde se conseguiu doações com a Universidade de teclados e mouses de computadores para ajudar a compor o projeto da coordenação da futura sala de informática para os usuários. Como também foi ofertados kits de higiene corporal e de primeiros socorros para atender as necessidades percebidas durante as ações desenvolvidas no serviço, primando pela melhoria do bem estar dos usuários.

A experiência do trabalho conjunto entre a enfermagem e a equipe multiprofissional do Centro de Referência Especializado para População em Situação de Rua de um município do interior do Ceará configurou-se no desenvolvimento de um trabalho amplo, proporcionando maior suporte aos usuários. Dessa forma destaca-se a relevância das ações de fortalecimento da integração ensino-serviço-comunidade, de modo a facilitar essa aproximação e qualificar o cuidado prestado às populações.

Consequentemente, os profissionais de saúde com o objetivo de promover uma assistência de qualidade devem estar abertos e conscientes das demandas que surgem pelos diferentes sujeitos que se encontram nas ruas, desempenhando a condição de acolhedores, além do importante papel de educadores em saúde. Levando em consideração os diferentes profissionais responsáveis pela assistência aos moradores de rua, o enfermeiro tem a educação em saúde como a principal ferramenta de atuação e como função primordial. Através dela e levando sempre em consideração as dimensões envolvidas (pessoal, física, psicológica, social, econômica, família), este profissional deve buscar a promoção da conscientização dos indivíduos com o objetivo de que eles desenvolvam o autoconhecimento, a autoconfiança e o autocuidado (SILVA et al., 2017).

\section{CONCLUSÃO}

Com as ações desenvolvidas no Centro de Referência Especializado para População em Situação de Rua de um município do interior do Ceará foi perceptível a importância da equipe multiprofissional que atua no serviço e que a mesma pode ser aperfeiçoada com a inclusão de outros profissionais como o enfermeiro, com vistas a uma assistência de saúde especializada e mais próxima à realidade dessas pessoas.

Logo, essas vivências contribuíram para a melhor visualização do indivíduo na sua totalidade, dando enfoque não apenas para as mazelas físicas, mas atentando-se prontamente para os aspectos comportamentais, psicológicos e emocionais dos indivíduos. Houve também uma significativa desconstrução de preconceitos até então existentes, promovendo um crescimento pessoal e profissional para os acadêmicos. 
Assim, é válido ressaltar a relevância dessas intervenções, tanto para os acadêmicos como para os participantes do Centro de Referência Especializado para População em Situação de Rua de um município do interior do Ceará, por meio de uma assistência multiprofissional e holística, visando à melhoria das condições de saúde e de vida dessas pessoas em situação de rua, levando em consideração as suas realidades cotidianas e compreendendo as especificidades de cada indivíduo.

\section{REFERÊNCIAS}

ALCANTARA, S. C.; ABREU, P. D.; FARIAS, A. A. Pessoas em situação de rua: das trajetórias de exclusão social aos processos emancipatórios de formação de consciência, identidade e sentimento de pertença. Revista Colombiana de Psicología, v. 24, n. 1, p. 129-143, 2015.

BRASIL. Ministério da Saúde. Secretaria de Gestão Estratégica e Participativa, Departamento de Apoio à Gestão Participativa. Saúde da população em situação de rua: um direito humano. Brasília: Ministério da Saúde, 2014.

FERRAZ, R. C. S. N. et al. Saberes e experiência: formação de professores da rede pública em atividades extensionistas. Revista Conexão UEPG, Ponta Grossa, v. 13, n. 3, set./dez. 2017.

NETO, A. P. S. Qualidade de vida de pessoas em situação de rua do Brasil Central. [Dissertação]. Universidade Federal de Goiás. Goiânia, 2016.

PAIVA, I. K. S. et al. Direito à saúde da população em situação de rua: reflexões sobre a problemática. Ciência \& Saúde Coletiva. v. 21, n. 8, p. 2595-2606, 2016. Disponível em: <https://doi.org/10.1590/1413-81232015218.06892015>. Acesso em: 3 mar. 2018.

RODRIGUES, A. L. L et al. Contribuições da extensão universitária na sociedade. Cadernos de Graduação: Ciências Humanas e Sociais. Aracaju, v. 1, n. 16, p. 141148, mar. 2013.

SILVA, H. S.; GUTIERREZ, B. A. O. Dimensões da qualidade de vida de idosos moradores de rua do município de São Paulo. Saúde e Sociedade. São Paulo, v. 22, n. 1, p. 148-159.

SILVA, R. P. et al. Assistência de enfermagem a pessoas em situação de rua. Revista Recien. São Paulo, v. 7, n. 20, p. 31-39, 2017.

Data de recebimento: 05 de março de 2018.

Data de aceite para publicação: 23 de abril de 2018. 